\title{
Extracorporeal treatment with high-volume continuous venovenous hemodiafiltration and charcoal-based sorbent hemoperfusion for severe metformin-associated lactic acidosis
}

\author{
Suneel Kumar Garg, Omender Singh, Desh Deepak, Akhilesh Singh, Rohit Yadav, Kirti Vashist
}

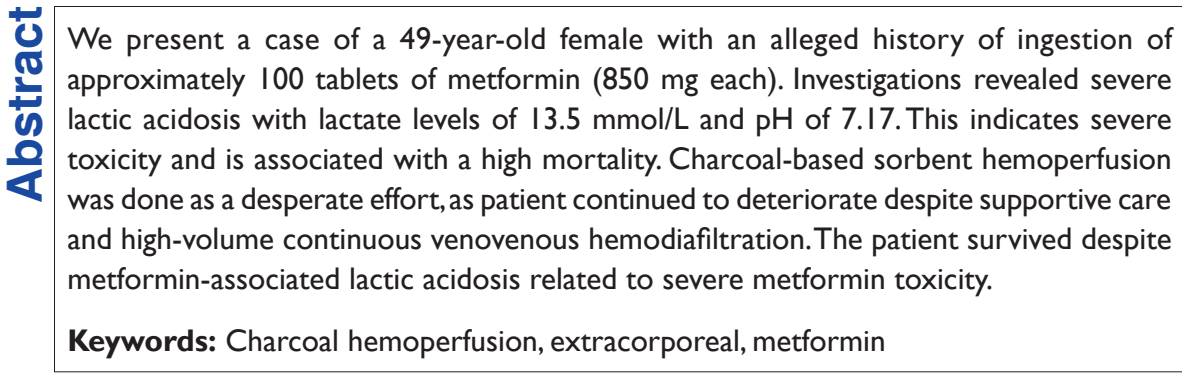

\section{Introduction}

Metformin is a biguanide antihyperglycemic agent commonly used as a glucose-lowering agent for the treatment of type-II diabetes mellitus and is considered safe. The potentially life-threatening complication of metformin overdose is metabolic acidosis described as metformin-associated lactic acidosis (MALA). There are only limited descriptions of metformin overdose in the literature. Early recognition, correction of metabolic acidosis, intensive support of the cardiovascular system, and maintenance of body temperature and drug removal, mainly by extracorporeal therapy, are the essential aspects of management as metformin is dialyzable. Patients who are treated with high-volume continuous venovenous hemodiafiltration (CVVHDF) have a better outcome. As per the American Association of Poison Centre (2004), only few patients $(0.05 \%)$ needed

From:

Institute of Critical Care Medicine, Max Super Speciality Hospital, Saket,

New Delhi, India

\section{Correspondence:}

Dr. Suneel Kumar Garg, Institute of Critical Care Medicine,

Max Super Speciality Hospital, Saket, New Delhi - 110 017, India.

E-mail: dr_garg@ hotmail.com

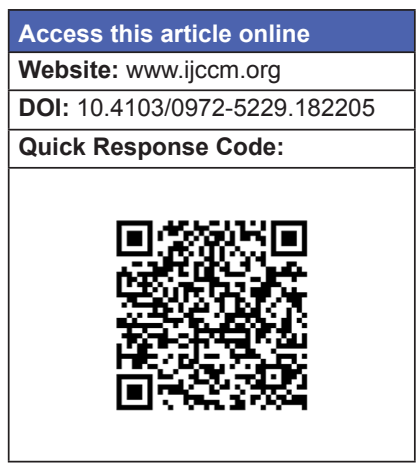

extracorporeal treatment for poisoning. ${ }^{[1]}$ Extracorporeal treatment, particularly charcoal-based, may be lifesaving in patients with clinical evidence of severe toxicity such as lactic acidosis, shock, and hypoglycemia in patients who are not responding to supportive management.

\section{Case Report}

A 49-year-old female, known case of type-II diabetes mellitus (on insulin), portal hypertension, and rheumatic heart disease, was admitted with an alleged history of consumption of 100 tablets of metformin $(850 \mathrm{mg}$ each, total dose $85 \mathrm{~g}$ ) around $2 \mathrm{~h}$ prior to presentation. She presented with nausea, vomiting, and shortness of breath. On admission, she was conscious, heart rate was

This is an open access article distributed under the terms of the Creative Commons Attribution-NonCommercial-ShareAlike 3.0 License, which allows others to remix, tweak, and build upon the work non-commercially, as long as the author is credited and the new creations are licensed under the identical terms.

For reprints contact: reprints@ medknow.com

How to cite this article: Garg SK, Singh O, Deepak D, Singh A, Yadav R, Vashist K. Extracorporeal treatment with high-volume continuous venovenous hemodiafiltration and charcoal-based sorbent hemoperfusion for severe metformin-associated lactic acidosis. Indian J Crit Care Med 2016;20:295-8. 
$88 / \mathrm{min}$, blood pressure was $80 / 40 \mathrm{mmHg}$, respiratory rate was $28 / \mathrm{min}$, and was afebrile. Her random blood sugar was $88 \mathrm{mg} \%$ on admission. Her arterial blood gas revealed severe metabolic acidosis with hyperlactatemia (pH 7.17 with lactate of $13.5 \mathrm{mmol} / \mathrm{l}$ ). She was intubated electively, and appropriate fluid resuscitation was done. In view of persistent hypotension, she was started on vasopressors. Gastric lavage was done with $100 \mathrm{~g}$ of activated charcoal in emergency room. She was shifted to Intensive Care Unit for further management. She was continued on vasopressors and started on $50 \%$ dextrose and $7.5 \%$ sodium bicarbonate infusions. She developed repeated episodes of hypoglycemia despite $50 \%$ dextrose infusion, and hence, glucagon bolus $2 \mathrm{mg}$ followed by 1-2 $\mathrm{mg} / \mathrm{h}$ infusion to target blood sugar level $>100 \mathrm{mg} \%$ was initiated. She was also started on high-flow CVVHDF. Hyperlactatemia gradually worsened with increasing levels $(13.5,15,22,24$, and $27 \mathrm{mmol} / \mathrm{l})$ over $8 \mathrm{~h}$ [Chart 1]. In view of refractory hypoglycemia and refractory metabolic acidosis, charcoal-based sorbent hemoperfusion was started as rescue therapy [Figure 1] and high-volume CVVHDF was continued.

The patient's condition started improving with increase in mean arterial blood pressure and decreasing lactate [Chart 1] around $6 \mathrm{~h}$ after starting charcoal-based sorbent hemoperfusion. Another session of charcoal-based sorbent hemoperfusion was given after $12 \mathrm{~h}$. Hypoglycemia and lactate levels gradually improved over the next $24 \mathrm{~h}$. Vasopressors, 50\% dextrose, glucagon,

\begin{tabular}{|c|c|c|c|c|c|}
\hline \multicolumn{6}{|c|}{ Chart I: Serial arterial blood gas } \\
\hline Date and time & $\mathrm{pH}$ & $\mathrm{PCO}_{2}$ & $\mathrm{PO}_{2}$ & $\mathrm{HCO}_{3}$ & Lactate \\
\hline February II, 20I5, 03.07 am & 7.172 & 36.2 & 94.6 & 12.8 & 13.5 \\
\hline February II, 2015, $04.26 \mathrm{am}$ & 7.109 & 38 & 107 & 10.9 & 15 \\
\hline February $11,2015,06.13 \mathrm{am}$ & 7.069 & 26.5 & III & 7.3 & 22 \\
\hline February II, 2015, $09.50 \mathrm{am}$ & 7.056 & 17.5 & 209 & 4.7 & 24 \\
\hline February II, 2015, $10.38 \mathrm{am}$ & 6.971 & 21.4 & 203 & 4.7 & 27 \\
\hline February II, 2015, $12.14 \mathrm{pm}$ & 6.939 & 25.9 & 158 & 5.3 & 25 \\
\hline February II, 2015, $03.08 \mathrm{pm}$ & 7.153 & 28.3 & 132 & 9.5 & 21 \\
\hline February II, 2015, 05.17 pm & 7.117 & 31.1 & 134 & 9.6 & 20 \\
\hline February II, 2015, $07.20 \mathrm{pm}$ & 7.231 & 38.9 & 138 & 15.7 & 13.5 \\
\hline February II, 2015, $10.11 \mathrm{pm}$ & 7.302 & 37 & 143 & 17.8 & 10.6 \\
\hline February $12,2015,01.16$ am & 7.308 & 40.3 & 112 & 19.6 & 8.9 \\
\hline February $12,2015,04.13 \mathrm{am}$ & 7.369 & 36.2 & 106 & 20.4 & 8.3 \\
\hline February $12,2015,08.34$ am & 7.392 & 39.9 & 128 & 23.7 & 5.6 \\
\hline February $12,2015,12.52 \mathrm{pm}$ & 7.465 & 33.5 & 143 & 23.7 & 4.3 \\
\hline February $12,2015,05.52 \mathrm{pm}$ & $7.50 \mathrm{I}$ & 28.4 & 134 & 22 & 2.2 \\
\hline February $12,2015,11.21 \mathrm{pm}$ & 7.538 & 30.2 & 118 & 25.6 & 2.3 \\
\hline February I3, 2015, 04.03 am & 7.487 & 36.3 & 89.1 & 27.1 & 1.7 \\
\hline February $13,2015,03.18 \mathrm{pm}$ & $7.44 I$ & 35.3 & 90.6 & 23.6 & 1.4 \\
\hline February $13,2015,07.31 \mathrm{pm}$ & 7.477 & 37.7 & $|4|$ & 27.5 & 1.8 \\
\hline February $13,2015,10.34 \mathrm{pm}$ & 7.454 & 41.7 & 71.5 & 28.8 & 1.9 \\
\hline February $14,2015,04.16$ am & 7.448 & 39.8 & 113 & 27.1 & 1.0 \\
\hline February I4, 20I5, $08.49 \mathrm{pm}$ & 7.491 & 35.4 & 64.1 & 26.8 & 1.6 \\
\hline February $15,2015,04.50 \mathrm{am}$ & 7.514 & 37.5 & 90.8 & 30 & I.I \\
\hline February $15,2015,09.15 \mathrm{pm}$ & $7.47 \mid$ & 37.1 & 73.6 & 26.7 & 1.5 \\
\hline February $16,2015,04.33$ am & 7.519 & 40 & 62 & 32.4 & I.I \\
\hline
\end{tabular}

and sodium bicarbonate were progressively weaned off in the next $48 \mathrm{~h}$ and stopped on day 3. CVVHDF without charcoal hemoperfusion was continued for the next $72 \mathrm{~h}$ and stopped after that as shock resolved, and acid-base status became normal [Chart 1]. The patient was extubated on day 4 and discharged on day 6 in stable condition with psychological consultation and counseling.

\section{Discussion}

Metformin is an antihyperglycemic agent of biguanide class used for the treatment of type-II diabetes mellitus. Metformin has a low bioavailability and takes a long time (around $6 \mathrm{~h}$ ) to get completely absorbed from gastrointestinal tract. There are case reports of fatal intoxication with metformin with varying dosage, i.e., $60 \mathrm{~g},{ }^{[2]} 76.5 \mathrm{~g}{ }^{[3]}$ and $100 \mathrm{~g} \cdot{ }^{[4,5]}$ In our case, the patient had consumed $85 \mathrm{~g}$. Metformin decreases blood glucose in diabetic patients, causes weight loss, improves lipid profile, and also causes a reduction in blood pressure. ${ }^{[6]}$

Patients with metformin overdose usually present with abdominal pain, nausea, and vomiting. Hypoglycemia is rarely reported with biguanide exposure. ${ }^{[7]}$ MALA is a life-threatening complication of metformin, which occurs either in cases of therapeutic dose or overdose or with concomitant risk factors, i.e., renal failure, liver and cardiovascular diseases, infection and alcoholics, and has a high mortality rate. ${ }^{[8]}$ Metformin intoxication is known to cause acute renal failure, which aggravates toxicity. ${ }^{[9]}$ With lactic acidosis, patients usually present with tachypnea, lethargy, hypotension, tachycardia, and shock, ${ }^{[10]}$ if not treated in time, death is unavoidable. The estimated rate of MALA from previous studies is believed to range somehow between 4 and 9 cases per 100,000 patient-years. ${ }^{[11]}$ Serum lactate levels do not

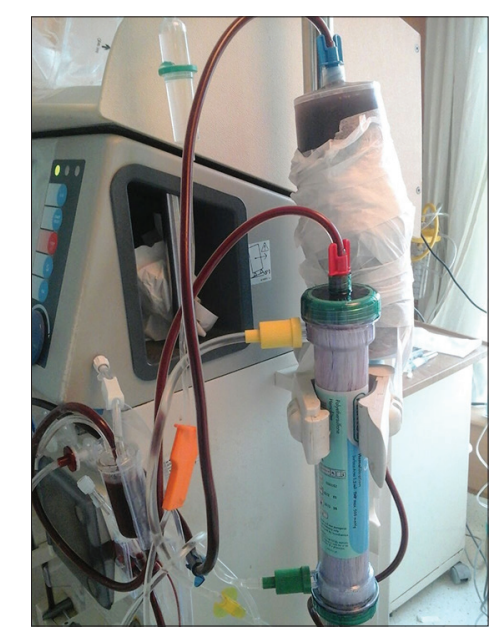

Figure I: Extracorporeal therapy with continuous venovenous hemodiafiltration and charcoal-based sorbent hemoperfusion 
correlate with prognosis. The pathogenesis of MALA is complex and not completely understood. ${ }^{[12]}$ In our case also, the patient presented with nausea, vomiting, hypotension, and severe lactic acidosis.

Management of metformin toxicity is supportive and includes gastrointestinal decontamination, correction of acid-base abnormalities, hypoglycemia, and hemodialysis. ${ }^{[6]}$ There is no specific antidote for metformin overdose. Hemodialysis should be performed in cases of lactic acidosis or impaired renal function. ${ }^{[13,14]}$

Success of hemodialysis depends on characteristics of the toxin, i.e., lipid solubility, molecular weight, volume of distribution, protein binding, and technique used for hemodialysis. ${ }^{[15]}$ Metformin has a low volume of distribution, molecular weight of $166 \mathrm{Da}$, and has almost negligible plasma protein binding, hence hemodialysis is an effective modality for removal of metformin..$^{[10]}$

In this patient, gastric lavage, activated charcoal, and other supportive care were given, and CVVHDF was initiated in view of shock and persistent lactic acidosis. In spite of CVVHDF, the patient had persistent shock, hyperlactatemia, and hypoglycemia and hence, charcoal-based sorbent hemoperfusion was incorporated along with CVVHDF. Till date, there is no report of using combination therapy with hemodiafiltration and hemoperfusion in metformin toxicity in the literature searched.

Despite their efficacy, the use of hemoperfusion cartridges has declined over the past 20 years, due to limitations of their indications and shelf life. To be removed by hemoperfusion, the toxic substance must have binding affinity to the sorbent in the cartridge and a low volume of distribution.

We used this modality as metformin meets all the characteristics required for efficient removal by charcoal sorbent. We continued CVVHD along with charcoal hemoperfusion because hemoperfusion lacks the efficacy of correcting acid-base, fluid, and electrolyte abnormalities. ${ }^{[16]}$ The patient's condition started improving around $6 \mathrm{~h}$ after starting charcoal-based sorbent hemoperfusion. We also gave another session of charcoal-based sorbent hemoperfusion with CVVHDF after $12 \mathrm{~h}$. Shock, hyperlactatemia, and hypoglycemia gradually improved and the patient weaned from the ventilator and extubated on day 4 . The patient was discharged on day 6 in stable condition.

\section{Conclusion}

Metformin seems to cause more hypoglycemia than reported in literature and may be an important sign of severe toxicity. Although lactic acidosis associated with severe metformin toxicity can result in high morbidity and mortality, most of them may not require aggressive treatment including hemodialysis.

Acute metformin overdose is potentially life-threatening condition, and patients may have rapid clinical deterioration and death, if not treated in a timely manner. Patients with metformin toxicity and MALA should be treated aggressively with supportive measures and hemodialysis. Given the high mortality rate, patients who have refractory hyperlactatemia, refractory shock, and refractory hypoglycemia even with best supportive care and hemodialysis should be subjected to CVVHDF with charcoal-based sorbent hemoperfusion. Charcoal-based sorbent hemoperfusion may be lifesaving in such clinical scenario.

\section{Financial support and sponsorship \\ Nil.}

\section{Conflicts of interest}

There are no conflicts of interest.

\section{References}

1. Watson WA, Litovitz TL, Rodgers GC Jr., Klein-Schwartz W, Reid N, Youniss J, et al. 2004 Annual report of the American Association of poison control centers toxic exposure surveillance system. Am J Emerg Med 2005;23:589-666

2. Suchard JR, Grotsky TA. Fatal metformin overdose presenting with progressive hyperglycemia. West J Emerg Med 2008;9:160-4.

3. Akinci B, Yener S, Bengi G, Yesil S. Alterations of coagulation in metformin intoxication. Hormones (Athens) 2008;7:325-9.

4. Aghabiklooei A, Mostafazadeh B, Shiva H. A fatal case of metformin intoxication. Pak J Med Sci 2011;27:943-4.

5. Basturk T, Balkan B, Aytekin M, Unsal A, Alagol A. Lactic acidosis due to metformin overdose. What treatment should be? A case report and review of the literature. BAN'TAO J 2009;7:44-6.

6. Campbell IW, Howlett HC. Worldwide experience of metformin as an effective glucose-lowering agent: A meta-analysis. Diabetes Metab Rev 1995;11 Suppl 1:S57-62.

7. Brady WJ, Carter CT. Metformin overdose. Am J Emerg Med 1997;15:107-8.

8. Chang CT, Chen YC, Fang JT, Huang CC. Metformin-associated lactic acidosis: Case reports and literature review. J Nephrol 2002;15:398-402.

9. Galea M, Jelacin N, Bramham K, White I. Severe lactic acidosis and rhabdomyolysis following metformin and ramipril overdose. $\mathrm{Br} \mathrm{J}$ Anaesth 2007;98:213-5.

10. Teale KF, Devine A, Stewart H, Harper N.J. The management of metformin overdose. Anaesthesia 1998;53:698-701.

11. Stang M, Wysowski DK, Butler-Jones D. Incidence of lactic acidosis in metformin users. Diabetes Care 1999;22:925-7.

12. Misbin RI. Phenformin-associated lactic acidosis: Pathogenesis and treatment. Ann Intern Med 1977;87:591-5. 
13. Alivanis P, Giannikouris I, Paliuras C, Arvanitis A, Volanaki M, Zervos A. Metformin-associated lactic acidosis treated with continuous renal replacement therapy. Clin Ther 2006;28:396-400.

14. Guo PY, Storsley LJ, Finkle SN. Severe lactic acidosis treated with prolonged hemodialysis: Recovery after massive overdoses of metformin. Semin Dial 2006;19:80-3.
15. Orlowski JM, Hou S, Leikin JB. Extracorporeal removal of drugs and toxins. In: Ford M, Delaney KA, Ling L. editors. Clinical Toxicology. $1^{\text {st }}$ ed. St. Louis, MO: WB Saunders Company; 2001. p. 43-50.

16. Shalkham AS, Kirrane BM, Hoffman RS, Goldfarb DS, Nelson LS. The availability and use of charcoal hemoperfusion in the treatment of poisoned patients. Am J Kidney Dis 2006;48:239-41. 